\title{
LUMINESCENT MACROCYCLIC LANTHANIDE COMPLEXES BEARING N-OXIDES: POTENTIAL FLUORESCENT LABELS FOR MODERN MEDICAL DIAGNOSTICS
}

\author{
M. Pietraszkiewicz, J. Karpiuk, R. Gąsiorowski, O. Pietraszkiewicz \\ and AsHoK Kumar Rout \\ Institute of Pliysical Chemistry, Polish Academy of Sciences \\ Kasprzaka 44/52, 01-224 Warsaw, Poland
}

\begin{abstract}
Macrocyclic and macropolycyclic ligands incorporating heteroaromatic $\mathrm{N}$-oxides $\left(3,3^{\prime}\right.$-biisoquinoline-2, $2^{\prime}$-dioxide) form strongly luminescent complexes with lanthanide ions: $\mathrm{Eu}(\mathrm{III})$ and $\mathrm{Tb}(\mathrm{III})$. Most of these complexes are stable water solutions, with excellent luminescent properties, regarding luminescence lifetimes in the range of $0.2-0.7 \mathrm{~ms}$, and the quantum yields for emission up to 0.25 . Several complexes are stable also in the presence of affecting ions, such as $\mathrm{Ca}(\mathrm{II})$, or phosphates. These features make them attractive as potential fluorescent labels for time-resolved fluoroimmunoassays.
\end{abstract}

PACS numbers: $33.50 . \mathrm{Dq}, 78.55 . \mathrm{Kz}, 82.50 . \mathrm{Fv}$

\section{Introduction}

Modern medical diagnostics requires methodologies featuring very high sensitivity and selectivity. Ones of the best known were the methods based on radiopharmaceuticals, or radionuclide-labelled bioconjugates, but the use of radionuclides has always imposed serious health hazards. Fluorescence spectroscopy in combination with labelled bioconjugates has been developed as a competitive methodology of comparable sensitivity and reliability. Although there are several techniques based on spectrofluorimetric methods, in this short paper we will present the lanthanide luminescent complexes as light-converting molecular devices, as potential luminescent labels for biological materials, such as monoclonal antibodies. These complexes act according to the absorption-energy transfer-emission (A-ET-E) process [1]. The lanthanide ion, typically $\mathrm{Eu}$ (III) or $\mathrm{Tb}(\mathrm{III})$, is surrounded by $\pi$-electronic system of heteroaromatic ligand. The UV excitation of the organic part leads to the singlet state $S_{1}$ which decays, giving the energy to the triplet state $T_{1}$ from which further radiationless energy transfer to the resonance level of the lanthanide ion results in the visible emission of the lanthanide cation. Figure 1 shows a simplified diagram for the A-ET-E process. Since the fluorescent 

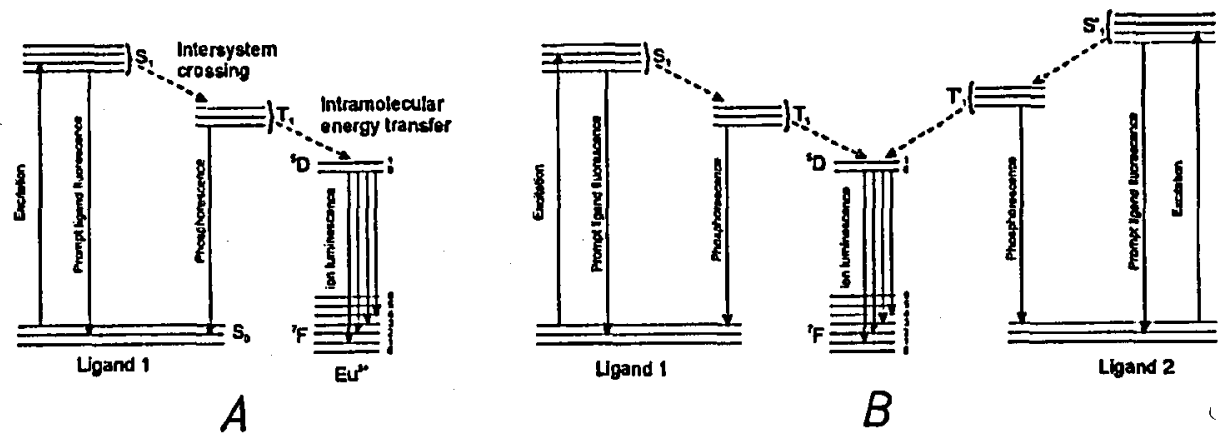

Fig. 1. Mechanisms for intramolecular energy transfer.

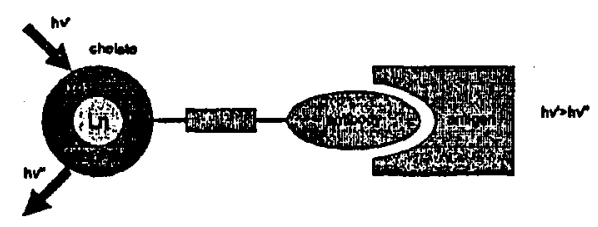

SEPARATED ASSEMBLY

GATED LUMINESCENCE COUNTING

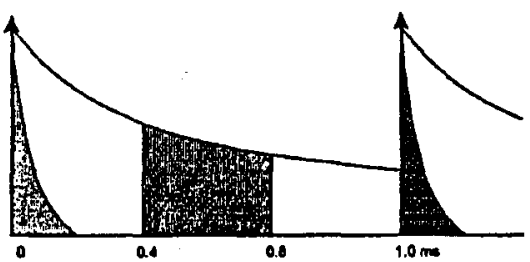

Fig. 2. The principle of fluoroimmunoassay.

labels are attached to biological materials, it is important to filter the short-lived emission of the aromatic units of biological material, thus the gated detection of the lanthanide emission is required, as schematically illustrated in Fig. 2.

Strong aromatic emission lasts in the nanoseconds range, whereas lanthanide ion emission is counted within $0.4-0.8 \mathrm{~ms}$. In the past decade several approaches have been developed to prepare stable in vivo lanthanide complexes. Two main approaches based on heterocyclic macrocyclic, or macropolycyclic receptors incorporating pyridine, phenanthroline, bipyridine, or biisoquinoline units [2]. Alternative methodology consisted on acyclic ligands incorporating ionizable groups as convergent ligating groups for the lanthanide ions [3]. Both methods ensured good stabilities and high kinetic inertness of complexes in water media. Encapsulation of the lanthanide ion in the macrobicyclic structure containing nitrogen donors provided not only high stabilities of the complexes formed through cooperative effects, though the $\mathrm{N}$-donors are poor ligands for lanthanide ions, but also prevented the water molecules from participating in the first coordination sphere of the lanthanide ion, which usually results in a loss of luminescence.

Much stronger ligands for lanthanide ions are heterocyclic N-oxides. Incorporation of $\mathrm{N}$-oxides into macrocyclic, or macropolycyclic network led to particu- . larly strong ligands for lanthanide complexation, and at the same time outstanding sensitizing properties, much better than the parent nitrogen-containing ligands [4]. Thus most of new $\mathrm{N}$-oxide-containing complexes fulfilled very strict requirements 

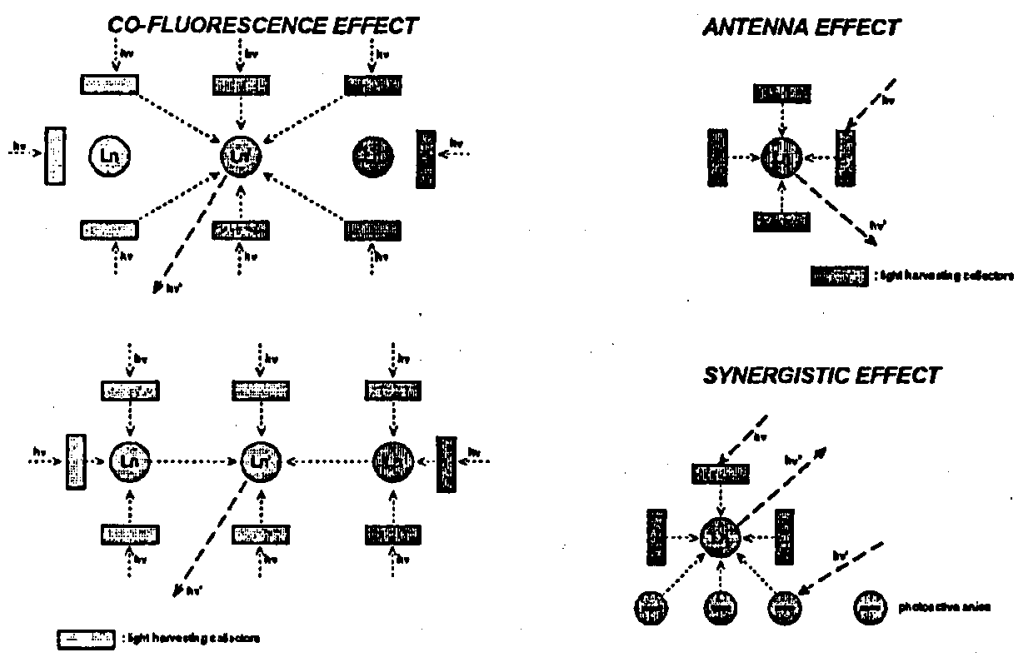

Fig. 3. Alternative ways to fluorescence quantum yields enhancements of the lanthanide sensitized emission.

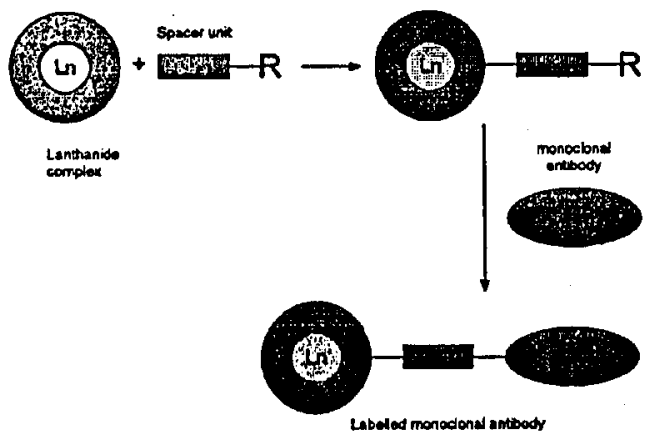

Fig. 4. The way of bioconjugate preparation.

imposed on luminescent lanthanide complexes as potential markers for bioconjugates. These requirements are the following:

- very high kinetic stability of lanthanide complexes in water media,

- high quantum yield for lanthanide emission,

- luminescence lifetime in the range of $0.4-0.8 \mathrm{~ms}$,

- high absorbance coefficient around $300 \mathrm{~nm}$,

- inertness for an exchange with affecting ions: $\mathrm{Ca}$ (II) and phosphates.

There are several additional methodologies allowing for further increase in the quantum yield for the lanthanide sensitized emission, and they are schematically depicted in Fig. 3. The principle of the bioconjugate preparation is represented in Fig. 4. 


\section{Results and discussion}

We have focused our efforts on the $3,3^{\prime}$-biisoquinoline-2, $2^{\prime}$-dioxide as a very powerful sensitizer for $\mathrm{Eu}(\mathrm{III})$ emission. Figure 5 shows several selected structures incorporating the above-mentioned unit, or units, and Table I collects the luminescent data for the Eu(III) complexes.

It is worth noting that the acyclic $\mathrm{Eu}$ (III) complex of the ligand 1 displayed the best quantum yield for emission that could not have been matched by other ligands. It is interesting also to say that the incorporation of more that one sensitizing unit into the ligand architecture was expected to increase the quantum yield, according to the "antenna effect" [5]. It was the case with the ligand 3, but two ligands with three units $(4 \mathrm{~A}, 4 \mathrm{~B})$ were particularly poor as sensitizers for the $\mathrm{Eu}(\mathrm{III})$ emission. This may be explained in terms of unfavourable coordination
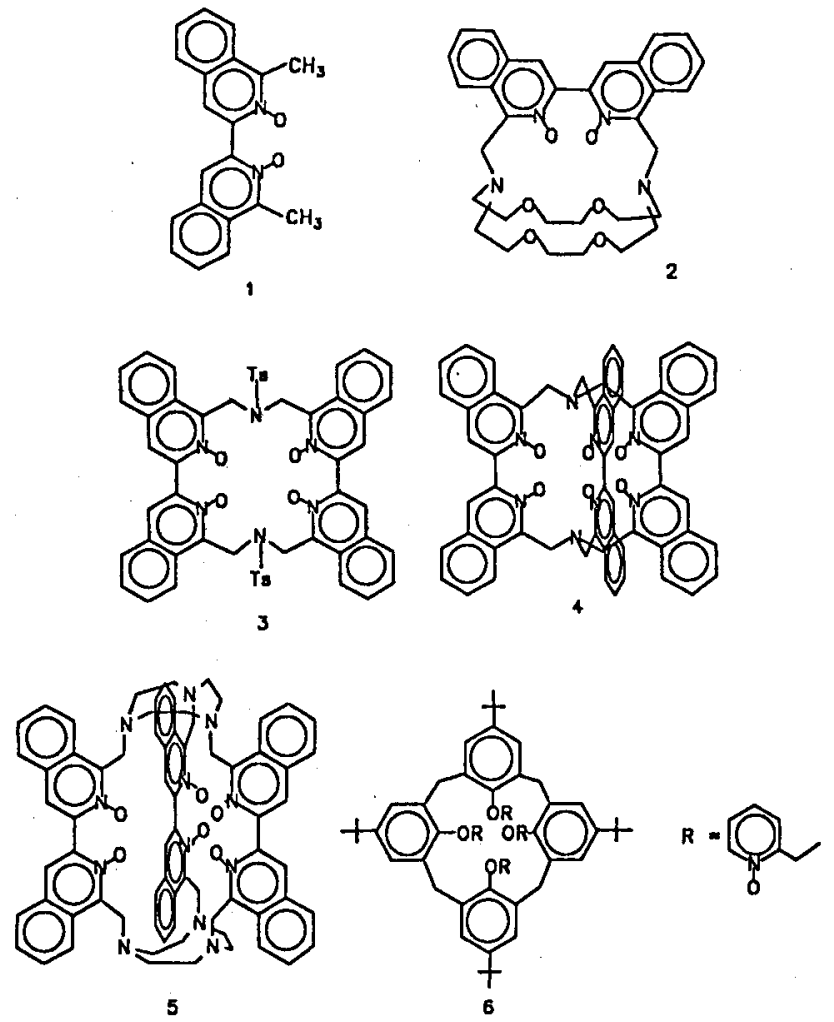

Fig. 5. Different macrocyclic and macropolycyclic ligands based on $3,3^{\prime}$-biisoquinoline-2, 2'-dioxide unit. Compound 1 taken as the reference compound for comparison of its sensitizing properties. 
TABLE I

Photophysical characteristics of the $\mathrm{Eu}(\mathrm{III})$ complexes in MeCN solution* at room temperature. Excitation at $337 \mathrm{~nm}$.

\begin{tabular}{|c|c|c|c|c|c|}
\hline $\begin{array}{l}\text { Ligand } \\
(L)\end{array}$ & $\begin{array}{l}\text { Eu(III) } \\
\text { salt }(S)\end{array}$ & $\begin{array}{l}L / S \\
\text { ratio }\end{array}$ & $\lambda_{\mathrm{em}}[\mathrm{nm}]$ & $\tau[\mathrm{ms}]$ & $\Phi$ \\
\hline 1 & $\mathrm{EuCl}_{3}$ & $2: 1$ & $592,618,700$ & 0.65 & 0.25 \\
\hline 2 & $\mathrm{EuCl}_{3}$ & $1: 1$ & $580,590,600,611,618,650$ & 0.62 & 0.057 \\
\hline 2 & $\mathrm{EuOTf}_{3}^{* *}$ & $"$ & $580,590,600,611,619,650$ & 0.70 & 0.17 \\
\hline 2 & $\mathrm{EuOTf}_{2} \mathrm{Br}$ & $"$ & $580,590,600,611,619,650$ & 0.52 & 0.138 \\
\hline 2 & $\mathrm{Eu}\left(\mathrm{ClO}_{4}\right)_{2} \mathrm{Br}$ & $"$ & $579,589,598,611,618,682$ & 0.64 & 0.04 \\
\hline 2 & $\operatorname{Eu}(\mathrm{DBM})^{* * *}$ & $"$ & $585,613,653,703$ & 0.26 & 0.023 \\
\hline 3 & $\mathrm{Eu}\left(\mathrm{ClO}_{4}\right)_{3}$ & $"$ & $580,590,595,614,618,650$ & 0.25 & 0.064 \\
\hline $4 \Lambda^{\#}$ & $\mathrm{EuOTf}_{3}$ & $"$ & $580,607,613,653,703$ & 0.25 & 0.002 \\
\hline $4 \mathrm{~B}^{\#}$ & $\operatorname{EuOTf}_{3}$ & $"$ & $580,594,607,652,703$ & 0.24 & 0.002 \\
\hline 5 & $\mathrm{EuOTf}_{3}$ & $"$ & $594,616,653,703$ & 0.14 & 0.001 \\
\hline 6 & $\mathrm{EuCl}_{3}$ & $"$ & $580,592,616,700$ & - & 0.003 \\
\hline 6 & $\mathrm{TbCl}_{3}$ & $"$ & $490,544,587,618$ & - & 0.002 \\
\hline
\end{tabular}

"spectra of 6 in MeOII; ${ }^{* *} \mathrm{OTf}=\mathrm{CF}_{3} \mathrm{SO}_{3} ;{ }^{* * *} \mathrm{DBM}=$ dibenzoylmethane; \# two diastereoisomers due to axial chirality of the $3,3^{\prime}$-biisoquinoline-2, $2^{\prime}$ -dioxide unit.

TABLE II

Relative fluorescence intensity upon addition of affecting ions.

\begin{tabular}{c|l|l|l|l}
\hline \hline \multicolumn{5}{c}{ EuOTf $_{3}$} \\
\hline $\begin{array}{c}\text { ion/complex } \\
\text { molar ratio }\end{array}$ & $\mathrm{CaCl}_{2}$ & $\mathrm{CaOTf}_{2}$ & $\mathrm{Na}_{3} \mathrm{PO}_{4}$ & $\mathrm{Et}_{4} \mathrm{NCl}$ \\
\hline 59 & 0.967 & 0.947 & 1.270 & 0.830 \\
& 0.987 & 0.983 & 1.197 & 0.777 \\
599 & $1.141^{*}$ & $1.12^{*}$ & - & $0.988^{*}$ \\
& $0.988^{* *}$ & 0.988 & $1.012^{* *}$ & $1.12^{* *}$ \\
\hline \multicolumn{5}{c}{$\left[6,6^{\prime} \text {-dicarboxy-2,2'-bipyridine }\right]_{3} \cdot\left(\mathrm{EuCl}_{3}\right)_{2}$} \\
\hline 54 & $0.840^{* * *}$ & - & $0.912^{* * *}$ & - \\
540 & $0.504^{* * *}$ & - & $0.794^{* * *}$ & - \\
\hline
\end{tabular}

*intensity after $2 \mathrm{~h} ;{ }^{* *}$ intensity after 3 days; ${ }^{* * *}$ no change after $2 \mathrm{~h}$, the values refer to the measurement after 3 days. 
pattern for the tight ligand $4 \mathrm{~A}$ and $\mathbf{4 B}$ around $\mathrm{Eu}(\mathrm{III})$ ion, or exclusive complex formation, where $\mathrm{Eu}$ (III) is partly exposed outside the cavity of the ligand, thus water molecules may penetrate the coordination sphere of the lanthanide ion, and quench significantly the fluorescence. On the other hand, larger cavity, as in case 5, may accommodate not only the lanthanide cation, but also several water molecules that participate in the first coordination sphere of lanthanide cation and quench the fluorescence to a remarkable degree.

It was also interesting to note that the influence of the anion on the luminescence quantum yield was significant, thus the proper choice of the counter-ion for $\mathrm{Eu}(\mathrm{III})$ may be beneficial to increase the overall output of the luminescence quantum yield.

Further studies involved the testing of two ligands: 2 and 6, 6'-dicarboxy-2, $2^{\prime}$ -bipyridine in form of mononuclear and dinuclear $\mathrm{Eu}$ (III) complexes, respectively. Table II shows the impact of added salts on the fluorescence intensity related to the unaffected emission of pure complexes (taken as a unit).

Either calcium or phosphates are present in physiological conditions. $\mathrm{Ca}$ (II) present in an excess may displace the $\mathrm{Eu}(\mathrm{III})$ ion, thus there will be a drop, or a loss of fluorescence. Phosphonate anions, on the other hand, may precipitate insoluble lanthanide phosphonates which leads to a loss of luminescence. In our case, macrobicyclic and acyclic complexes displayed excellent stabilities in water media containing a large excess of affecting ions. Thus it seems that these two complexes might be considered as good candidates for fluorescent lanthanide markers.

\section{Further perspectives}

It seems that there must be a compromise between the preorganization of the macrobicyclic ligand and its flexibility. Preorganization means that the receptor hardly adopts the conformation fitting the most efficient overlap of the lanthanide ion orbitals by electron pairs of heteroatom donors. This may account for relatively modest quantum yields for eniission. To the contrary, more freedom in fitting the ligand to the coordination pattern of the lanthanide ion may also increase the stability of the complex by tighter fit of the ligating units around the cation. Thus the ligand may be designed in the way that the core macrocyclic architecture may be substituted with photoactive pendant arms possessing remarkable flexibility to wrap up around the cation. This may be a challenging task for the future research.

\section{Acknowledgment}

This work was supported by the Committee for Scientific Research, grant No. 0207969101.

\section{References}

[1] E. Soini, T. Lövgren, CRC Critical Rev. Anal. Chem. 18, 105 (1987); I.A. Hemmilä, Applications of Fluorescence in Immunoassays, Wiley, New York 1991. 
[2] J.-C. Rodriguez-Ubis, B. Alpha, D. Plancherel, J.-M. Lehn, Helv. Chim. Acta 67, 2264 (1984); B. Alpha, J.-M. Leln, G. Mathis, Angew. Chem. Int. Ed. Engl. 26, 266 (1987); B. Alpha, V. Balzani, J.-M. Lehn, S. Perathoner, N. Sabbatini, Angew. Chem. Int. Ed. Engl. 26, 1266 (1987); B. Alpha, E. Anklam, R. Deschenaux, J.-M. Lehı, M. Pietraszkiewicz, Helv. Chim. Acta, 71, 1042 (1988); G. Blasse, G.J. Dirksen, N. Sabbatini, S. Perathoner, J.-M. Lehn, B. Alpha, J. Phys. Chem. 92, 2419 (1988); R. Ziessel, J.-M. Lehn, Helv. Chim. Acta 73, 1149 (1990); V. Balzani, E. Berghmans, J.-M. Lehn, N. Sabbatini, R. Terode, R. Ziessel, Helv. Chim. Acta 73, 2083 (1990); R. Ziessel, J.-M. Lehn, Helv. Chim. Acta 73, 1149 (1990); V. Balzani, E. Berghmans, J.-M. Lehn, N. Sabbatini, R. Terode, R. Ziessel, Helv. Chim. Acta 73, 2083 (1990).

[3] V.-M. Mukkala, C. Sund, M. Kwiatkowski, P. Pasanen, M. Hogberg, J. Kankare, H. Takalo, Helv. Chim. Acta 75, 1621 (1992); V.-M. Mukkala, J. Kankare, Helv. Chim. Acta 75, 1578 (1992); H. Takalo, E. Hanninen, J. Kankare, Helv. Chim. Acta 76, 877 (1993); V.-M. Mukkala, M. Kwiatkowski, J. Kankare, H. Takalo, Helv. Chim. Acta 76, 893 (1993); V.-M. Mukkala, M. Helenius, I. Hemmilä, J. Kankare, II. Takalo, Helv. Chim. Acta 7G, 1361 (1993).

[4] M. Pietraszkiewicz, S. Pappalardo, P. Finocchiaro, A. Mamo, J. Karpiuk, J. Chem. Soc., Chem. Commun. 1907 (1989); J.-M. Lehn, M. Pietraszkiewicz, J. Karpiuk, Helv. Chim. Acta 73, 106 (1990); S. Pappalardo, F. Bottino, L. Giunta, M. Pietraszkiewicz, J. Karpiuk, J. Incl. Phenom. Mol. Recogn. Chem. 10, 387 (1991); M. Pietraszkiewicz, J. Karpiuk, A.K. Rout, Pure Appl. Chem. 65, 563 (1993).

[5] B. Alpha, R. Ballardini, V. Balzani, J.-M. Lehn, S. Perathoner, N. Sabbatini, Photochem. Photobiol. 52, 299 (1990). 